\title{
Occurrence Frequencies and Regional Variations of Fire points in the southern China
}

\author{
Guanglin $\mathrm{Lai}^{1}$, Xiaoze $\mathrm{Xu}^{2}$, Haohui $\mathrm{Su}^{1, *}$, Qi Wang ${ }^{1}$, and Wenjian Zheng ${ }^{1}$ \\ ${ }^{1}$ Maintenance \& Test Center of CSG EHV Power Transmission Company, Guangzhou 510663, China \\ ${ }^{2}$ School of Atmospheric Physic, Nanjing University of Information Science and Technology, Nanjing 210044, China
}

\begin{abstract}
This paper employs Himawari-8 fire points data to analyze the annual, monthly and regional distribution of fire points in the five southern provinces (Guangdong, Guangxi, Yunnan, Guizhou, and Hainan). Results showed that from 2016 to 2020, the occurrence frequencies of fire points in Yunnan Province showed an increasing trend, while the occurrence frequencies in Guangdong Province showed a downward trend. The occurrence frequencies in Guizhou, Guangxi and Hainan did not change significantly. For the monthly scale, the occurrence frequencies of fire points are mainly concentrated in January-March in the southern China. The analysis results will provide reference for the prevention and control of fire accidents in the five southern provinces.
\end{abstract}

\section{Introduction}

In recent years, with the country's increasing emphasis on ecological and environmental protection, disaster prevention and other aspects, monitoring problems such as straw burning and open fire burning in urban public areas have become more prominent, and the detection and early warning of disasters such as natural forest fires and urban man-made fires have become more important. Large-scale fires can cause serious air pollution [1-2], soil degradation [3], and damage the natural environment and ecological balance [4], seriously threaten the safety of people's lives and property.

Fire is closely related to human activities, climate and weather [5-8], including frequent urban fires (eg., NotreDame Cathedral Fire in Paris), and large-scale vegetation burning caused by man in tropical areas [9-11] and fires caused by lightning in temperate and boreal regions [12]. At the same time, global warming and extreme weather events have further increased the frequency of fires [13]. $\mathrm{Li}$ et al. (2020) used VIIRS (Visible Infrared Imaging Radiometer Suite) data products to analyze the spatiotemporal characteristics of global fires. The study found that the highest frequency of fires occurred in tropical regions, and they are mainly concentrated in July to September [14].

Therefore, the monitoring and prevention of fires in South China is very important. Based on the Himawari- 8 satellite fire data, this paper analyzes the spatio-temporal characteristics of fires in five southern provinces (Guangdong, Guangxi, Yunnan, Guizhou, and Hainan). This research is of great significance for fire prevention in the five southern provinces.

\section{Data and methods}

Himawari-8 geostationary meteorological satellite has the characteristics of high spatial resolution, high frequency of observation and high timeliness, and it has strong advantages for fire points monitoring. This paper uses the fire points data from 2016 to 2020 in the geophysical parameters estimated by the JAXA P-Tree system based on the Himawari-8-L3 standard data, and the time resolution is one month, the spatial resolution is $0.25^{\circ}$. Based on these fire points data, this paper counts the annual and monthly changes of frequencies of fire points in five southern provinces from 2016 to 2020, and analyzes the regional distribution characteristics of fire points in each province.

\section{Results}

\subsection{Annual analyses}

According to Himawari-8 fire point data, the average annual occurrence frequencies of fire points in Yunnan, Guizhou, Guangxi, Hainan and Guangdong from 2016 to 2020 were up to $6.72,2.39,5.21,0.32$ and $4.44 \times 104$ (Figure1-a). Yunnan Province has the most occurrence frequencies of fire points, while Hainan Province has relatively few occurrence frequencies due to its small area. Figure1-b shows the annual changes of occurrence frequencies in the five southern provinces from 2016 to 2020. It can be found that during the five-year period, the occurrence frequencies of fire points in Guizhou, Guangxi and Hainan provinces did not change significantly, while the occurrence frequencies of fire points in Yunnan 
Province has an increasing trend. On the contrary, the occurrence frequencies of fire points in Guangdong Province have shown a downward trend. Except for Guangdong Province, the remaining four provinces had the most occurrence frequencies in 2019, while

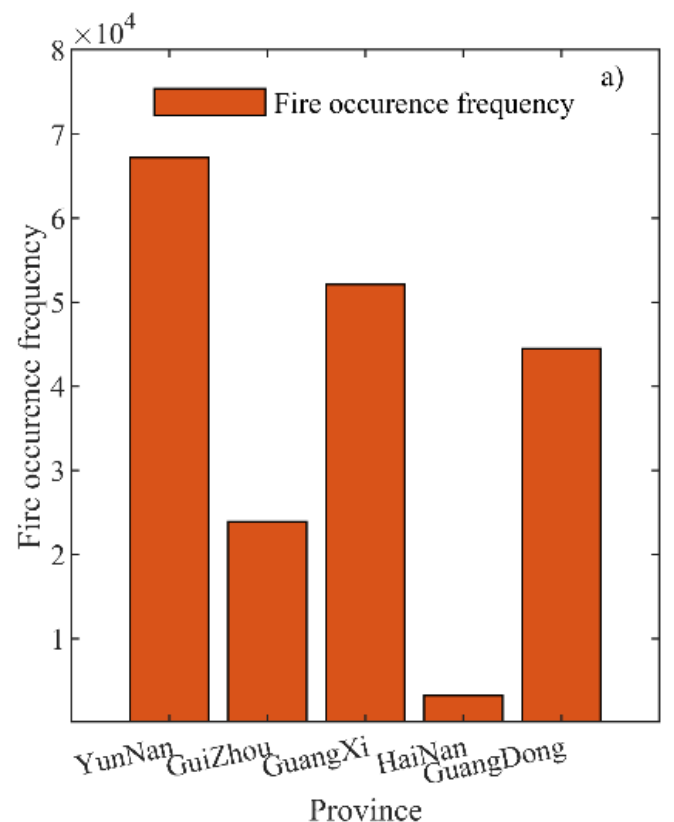

Guangdong Province had the most occurrence frequencies in 2017. In general, the occurrence frequencies of fire points are very common in the five southern provinces, and they are worthy of an in-depth, continuous, and comprehensive investigation.

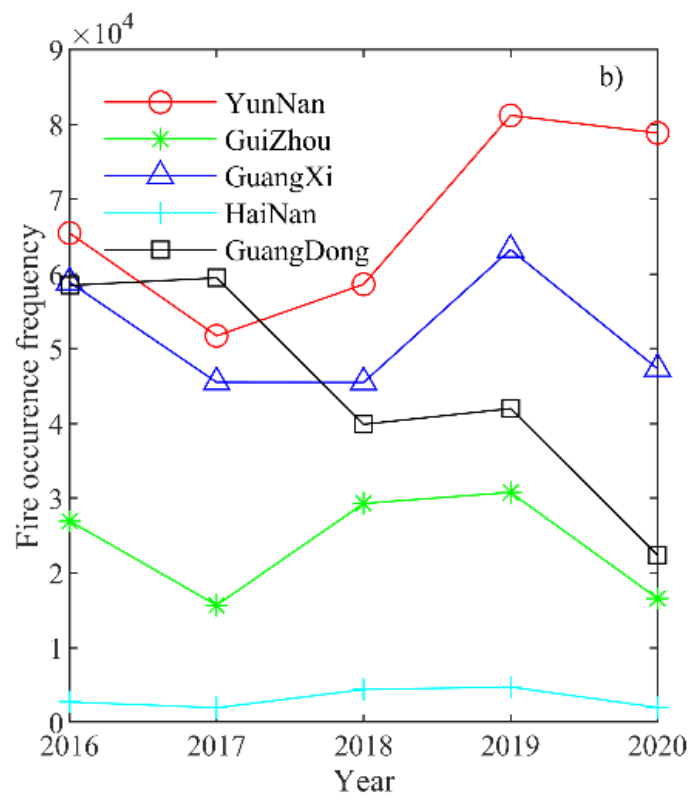

Figure1 Annual average occurrence frequencies of fire points (a) and annual change (b) in the five southern provinces

\subsection{Monthly analyses}

Figure 2 shows the average monthly changes in the number of fire points in the five southern provinces. It can be seen from the figure that the monthly changes of occurrence frequencies in Yunnan Province are in a unimodal distribution, mainly concentrated in January (13.65\%), February $(21.10 \%)$ and March $(21.48 \%)$, of which March has the most frequency, which is $1.44 \times 104$ times. JuneOctober is the low-value period of occurrence frequencies, accounting for only $4.57 \%$ of the total occurrence frequencies. The occurrence frequencies of fire points in Guizhou Province showed a bimodal distribution, mainly in February (29.62\%) and March (24.91\%). There are fewer occurrence frequencies from May to November, but it is worth noting that the number of occurrence frequencies in August is another peak $(9.44 \%)$. The monthly changes of occurrence frequencies in Guangxi and Guangdong provinces are very similar. The occurrence frequencies in the two provinces have a bimodal distribution, and they are located in February $(15.10 \%$ and $23.90 \%)$ and December $(25.27 \%$ and $19.53 \%)$. The low-value periods of occurrence frequencies are June-July and May-August respectively. The occurrence frequencies in Hainan Province showed a bimodal distribution, which was in March (17.17\%) and October $(25.90 \%)$. It is worth noting that the average occurrence frequencies in October in Hainan Province is much higher than the median value. This is due to the excessive occurrence frequencies of fire points in October 2018 and 2019 that led to the high average level. In general, the fires in the five southern provinces are mainly concentrated in the dry spring and winter. In summer, due to the high humidity, there are fewer fires. 

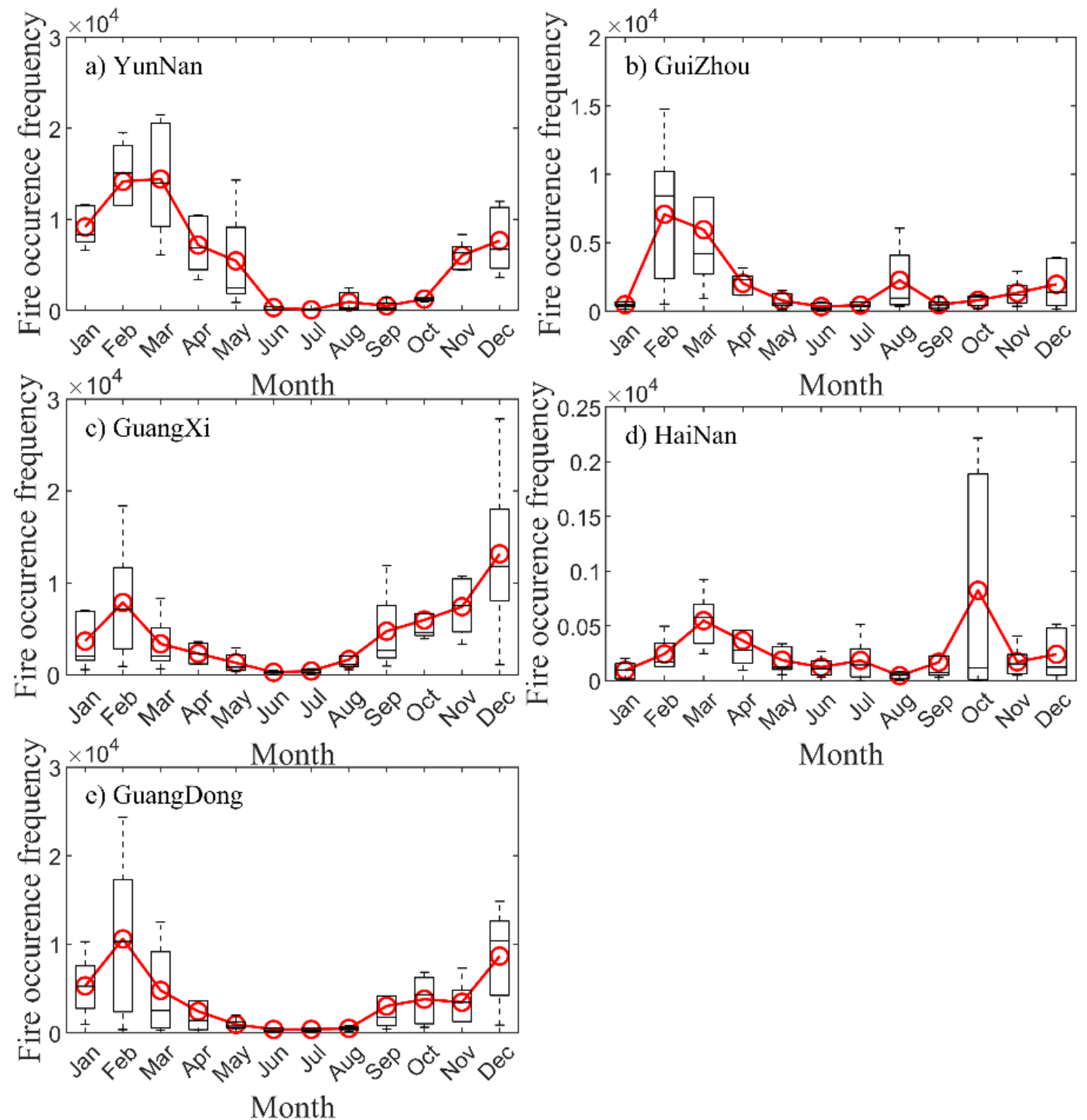

Month

\subsection{Regional distribution analyses}

Figure 3 shows the regional distribution characteristics of fire points in the five southern provinces. It can be seen that fire points in Yunnan Province are mainly concentrated in the southern areas, and in the areas south of $25^{\circ} \mathrm{N}$, the occurrence frequencies accounted for $79.51 \%$ of the total occurrence frequencies. The fire points in Guizhou Province are also mainly concentrated in the southern areas. The occurrence frequencies in the south of $25^{\circ} \mathrm{N}$ account for $91.09 \%$. The distribution of fire points in Guangxi Province is relatively scattered, with the eastern area slightly higher than the western area, and the occurrence frequencies in east of $109^{\circ} \mathrm{E}$ accounted for $63.06 \%$. Fire points in Hainan Province are mainly concentrated in the northwest region, and the occurrence frequencies in north of $19^{\circ} \mathrm{N}$ and west of $110^{\circ} \mathrm{E}$ account for $88.75 \%$. Fire points in Guangdong Province are mainly concentrated in the northerly areas, with fires north of $22^{\circ} \mathrm{N}$ accounting for $79.59 \%$. 

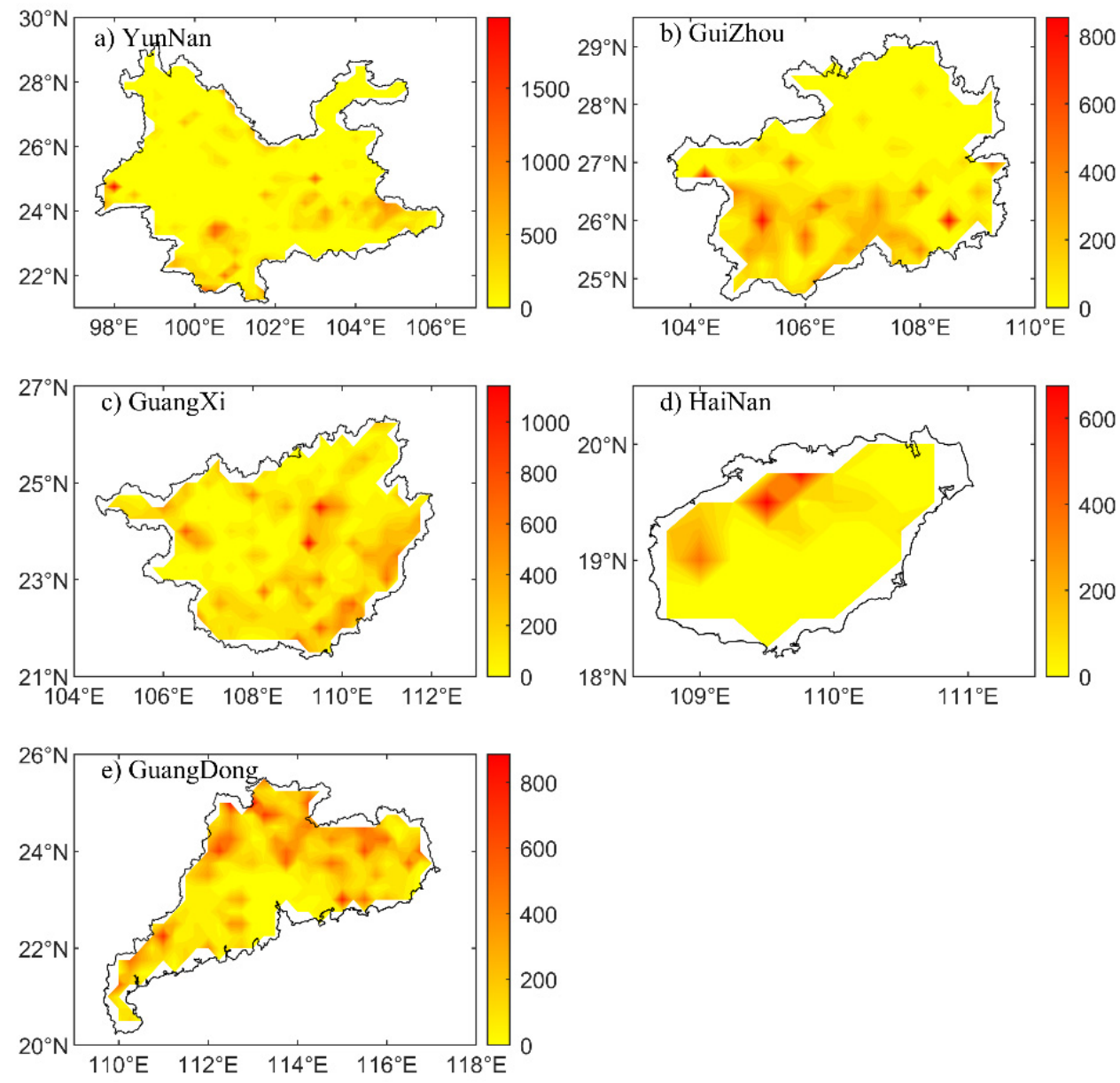

Figure3 Regional distribution of fire points in the five southern provinces 1482 (2000)

\section{Conclusions}

This paper uses Himawari-8 fire points data to analyze the annual, monthly and regional distribution of fire points in the five southern provinces. The results showed that from 2016 to 2020, the occurrence frequencies of fire points in Yunnan Province showed an increasing trend, while the occurrence frequencies in Guangdong Province showed a downward trend. The occurrence frequencies in Guizhou, Guangxi and Hainan did not change significantly. For the monthly scale, the occurrence frequencies of fire points in the five provinces of Yunnan, Guizhou, Guangxi, Hainan, and Guangdong are concentrated in January-March, February-February, February and December, March and October, and February and December, respectively. The regional distribution characteristics show that the fire points in Yunnan and Guizhou provinces are mainly concentrated in the south. The distribution of fire points in Guangxi Province is relatively scattered. Fire points in Hainan Province are mainly concentrated in the northwest region, and fire points in Guangdong Province are mainly concentrated in the northerly areas

\section{References}

1. L.Y. Chan, C.Y. Chan, H.Y. Liu, S. Christopher, S.J. Oltmans, J.M. Harris, Geophys. Res. Lett 27, 1479-
2. X. Zhang, A. Hecobian, M. Zheng, N.H. Frank, R.J. Weber, Atmospheric. Chem. Phys, 10, 6839-6853 (2010)

3. E.J. Bowd, S.C. Banks, C.L. Strong, D.B. Lindenmayer, Nat. Geosci 12, 113-118 (2019)

4. Y. Chang, H.S. He, I. Bishop, Y. Hu, R. Bu, C. Xu, X. Li, Int. J. Wildland. Fire 16, 34-44 (2007)

5. L. Dewilde, F. Iii, Ecosystems 9, 1342-1353 (2006)

6. G.J. Cary, R.E. Keane, R.H. Gardner, S. Lavorel, M.D. Flannigan, I.D. Davies, L. Chao, J.M. Lenihan, T.S. Rupp, F. Mouillot, Landscape. Ecol 21, 121-137 (2006)

7. M.D. Flannigan, M.A. Krawchuk, W.J. de Groot, B.M. Wotton, L.M. Gowman, Int. J. Wildland. Fire 18, 483507 (2009)

8. N.P. Gillett, A.J. Weaver, F.W. Zwiers, M.D. Flannigan. Geophys. Res. Lett 31, L18211 (2004)

9. J.G. Goldammer, Mitig. Adapt. Strat. Gl 12, 13-32 (2007)

10. D. Müller, S. Suess, A.A. Hoffmann, G. Buchholz, Hum. Ecol 41, 7-20 (2013)

11. K.P. Vadrevu, K. Lasko, L. Giglio, W. Schroeder, S. Biswas, C. Justice, Sci. Rep 9, 7422 (2019)

12. D.G. Woolford, C.B. Dean, D.L. Martell, J. Cao, B.M. Wotton, Environmetrics 25, 406-416 (2015) 
13. W.M. Jolly, M.A. Cochrane, P.H. Freeborn, Z.A. Holden, T.J. Brown, G.J. Williamson, D.M.J.S. Bowman, Nat. Commun 6, 1-11 (2015)

14. P. Li, C. Xiao, Z. Feng, W. Li, X. Zhang, Global. Change. Biol 26 (2020) 